\title{
Retrospective slice prescription compensation improves coronary cross-sectional area measurement by MRI
}

Travis Smith*, Krishna Nayak

From 2011 SCMR/Euro CMR Joint Scientific Sessions

Nice, France. 3-6 February 2011

\section{Objective}

To determine if vessel orientation can be estimated retrospectively, and if this information improves measurements of coronary luminal area.

\section{Background}

Measurements of coronary cross-sectional area are utilized in vasomotor tone and endothelial function studies, which typically employ breath-held, 2-D multi-slice imaging protocols wherein slices are prescribed orthogonally to a linear vessel segment (Fig 1a) [1],[2]. An ovoid template is then manually fitted to the transverse vessel images (Fig 1b) to measure cross-sectional area. Projection through the slice leads to dependencies between the measured area and the prescription angle (between the slice and the vessel-ideally $0^{\circ}$ ). This adds bias and reduces repeatability, which is problematic when detecting subtle dilations [3].

\section{Methods}

Cardiac-gated, breath-held spiral coronary angiography with spectral-spatial excitation was performed using a GE Signa 3T scanner (5 mm slice thickness, 16 interleaves, 5 slices). Transverse views of a cylindrical vessel phantom (diameter $=5 \mathrm{~mm}$, field-of-view $=5 \mathrm{~cm}$, resolution $=0.25 \mathrm{~mm}$ ) and a linear segment of the right coronary artery (RCA) in a healthy volunteer (diameter $=\sim 3.5$ $\mathrm{mm}$, field-of-view $=22 \mathrm{~cm}$, resolution $=0.7 \mathrm{~mm}$ ) were acquired, along with field maps, for gridding reconstruction and off-resonance deblurring [4]. We applied a segmented cylindrical model and estimated the prescription angle for each slice from the vessel displacement

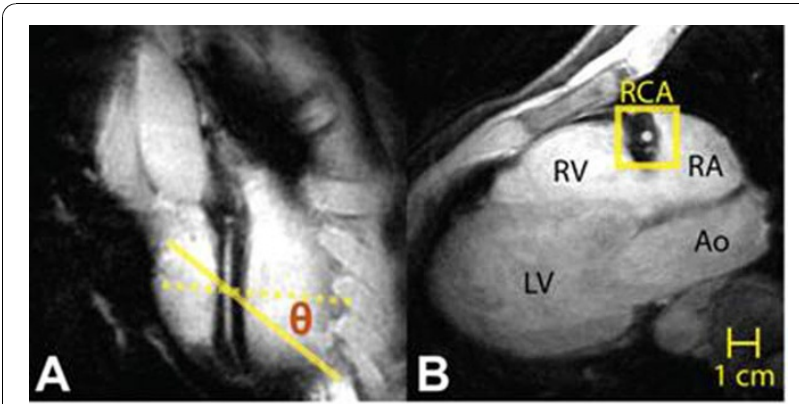

\section{C $\theta=\begin{array}{lllll}\theta & 0^{\circ} & 5.4^{\circ} & 10.3^{\circ} & 20.5^{\circ} \quad 31.5^{\circ}\end{array}$}

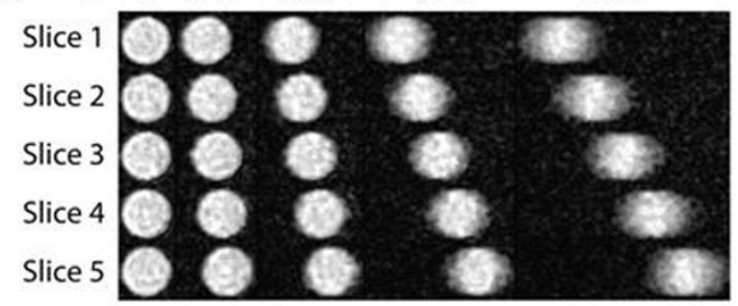

\section{D $\theta \approx 5^{\circ} \quad 15^{\circ} \quad 18^{\circ} \quad 24^{\circ} \quad 34^{\circ}$}

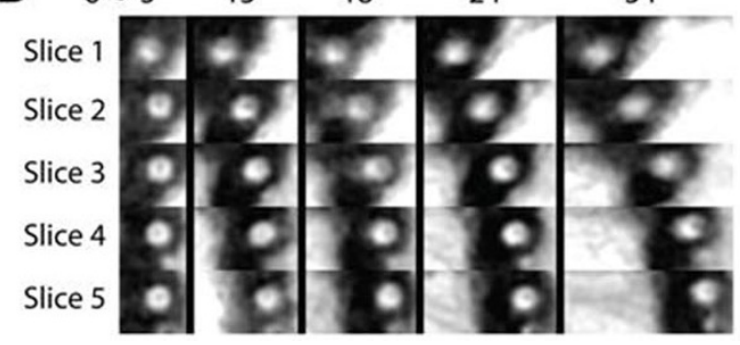

Figure 1 (a) Long axis view of a linear RCA segment with slice prescription angle $\theta$. (b) Cross-sectional image of the RCA. (c) Crosssectional images from the cylindrical vessel phantom. (d) Crosssectional images around the RCA for each estimated slice angle $\theta$. 


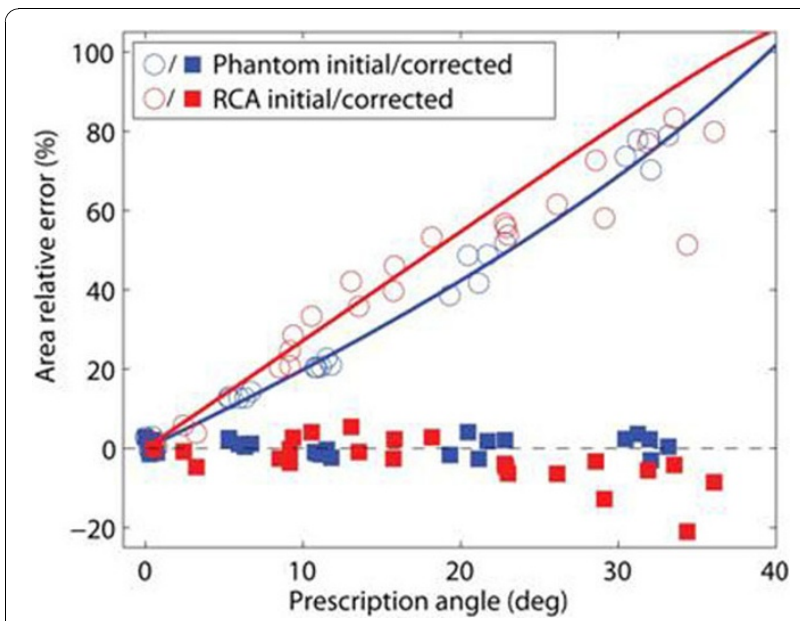

Figure 2 Relative error for each image in Figure $1 c, d$ for both initial (circle) and corrected (square) area measurements. The solid lines indicate the theoretical performance based on our geometric model. Relative error $=100 \times($ measured-true $) /$ true.

through the two neighboring slices. The measured cross-sectional areas were then geometrically compensated to correct any apparent ellipticity from non-orthogonal prescriptions. This process was repeated with several prescription angles ranging from $0^{\circ}$ to approximately $30^{\circ}$.

\section{Results}

Non-orthogonal prescription angles lead to slice-dependent elliptical projections of the cylindrical phantom (Fig 1c) and the RCA (Fig 1d). Ellipticity is also generated by changes in the local RCA shape, as seen in the $5^{\circ}$, slice 1 image. Our approach reduced area measurement error at every prescription angle (Fig 2). The approach is sensitive to angle estimation accuracy, and tends to underestimate area as seen in the high-angle in vivo results. A higher-order model of the vessel may

Table 1 Performance in the vessel phantom

\begin{tabular}{llllll}
\hline $\begin{array}{l}\text { True } \\
\text { angle } \\
\text { (deg) }\end{array}$ & $\begin{array}{l}\text { Estimated } \\
\text { angle } \\
\text { (deg) }\end{array}$ & $\begin{array}{l}\text { Area } \\
\text { relative } \\
\text { error \% } \\
\text { (initial) }\end{array}$ & $\begin{array}{l}\text { Area } \\
\text { relative } \\
\text { error \% } \\
\text { (corrected) }\end{array}$ & $\begin{array}{l}\text { Error- } \\
\text { equivalent } \\
\text { angle } \\
\text { (deg) }\end{array}$ & $\begin{array}{l}\text { Prescription } \\
\text { sensitivity } \\
\text { reduction } \\
\text { factor }\end{array}$ \\
\hline 0 & $0.3 \pm 0.1$ & $\begin{array}{l}0.7 \pm 2.0 \\
12.7 \pm\end{array}$ & $0.08 \pm 1.8$ & 0.04 & 0 \\
5.4 & $5.6 \pm 0.6$ & $\begin{array}{l}1.7 \pm 1.1 \\
0.3\end{array}$ & 0.9 & 6 \\
10.3 & $11.2 \pm 0.3$ & $\begin{array}{l}21.1 \pm \\
1.3\end{array}$ & $-1.0 \pm 0.6$ & 0.5 & 21 \\
20.5 & $20.3 \pm 0.9$ & $\begin{array}{l}43.0 \pm \\
5.1\end{array}$ & $-0.07 \pm 3.6$ & 0.04 & 512 \\
31.5 & $31.9 \pm 1.4$ & $\begin{array}{l}74.3 \pm \\
4.4\end{array}$ & $-0.06 \pm 2.7$ & 0.03 & 1050 \\
& & 4.4 & & \\
\hline
\end{tabular}

The error-equivalent angle is the prescription angle corresponding to the mean area error after correction (based on the solid lines in Fig. 2). The prescription sensitivity reduction factor is the ratio of the actual prescription angle to the error-equivalent angle.
Table 2 Performance in the RCA

\begin{tabular}{|c|c|c|c|c|c|}
\hline $\begin{array}{l}\text { True } \\
\text { angle } \\
\text { (deg) }\end{array}$ & $\begin{array}{l}\text { Estimated } \\
\text { angle } \\
\text { (deg) }\end{array}$ & $\begin{array}{l}\text { Area } \\
\text { relative } \\
\text { error \% } \\
\text { (initial) }\end{array}$ & $\begin{array}{l}\text { Area } \\
\text { relative } \\
\text { error \% } \\
\text { (corrected) }\end{array}$ & $\begin{array}{l}\text { Error- } \\
\text { equivalent } \\
\text { angle } \\
\text { (deg) }\end{array}$ & $\begin{array}{l}\text { Prescription } \\
\text { sensitivity } \\
\text { reduction } \\
\text { factor }\end{array}$ \\
\hline & $4.5 \pm 5.3$ & $\begin{array}{l}13.5 \pm \\
17.4\end{array}$ & $1.0 \pm 2.6$ & 0.4 & 11 \\
\hline & $15.1 \pm 7.1$ & $\begin{array}{l}40.2 \pm \\
14.6\end{array}$ & $-0.4 \pm 5.9$ & 0.2 & 75 \\
\hline & $17.8 \pm 10.4$ & $\begin{array}{l}41.5 \pm \\
19.3\end{array}$ & $-4.4 \pm 7.7$ & 1.6 & 11 \\
\hline & $23.5 \pm 8.1$ & $\begin{array}{l}57.8 \pm \\
18.7\end{array}$ & $-4.0 \pm 1.5$ & 1.5 & 16 \\
\hline & $33.5 \pm 7.4$ & $\begin{array}{l}80.4 \pm \\
17.6\end{array}$ & $-5.3 \pm 1.1$ & 2.0 & 17 \\
\hline
\end{tabular}

improve estimation performance. Nonetheless, the error performance after correction was equivalent to acquiring with much smaller prescription angles (Tables 1,2). The median in vivo improvement in the sensitivity reduction was 16 -fold.

\section{Conclusions}

Cross-sectional lumen area can be retrospectively compensated for non-orthogonally prescribed slices, thereby reducing the sensitivity to slice prescription and breathhold repeatability. This approach should reduce operator dependence and shorten localization time.

Published: 2 February 2011

\section{References}

1. Terashima, et al: JACC 2005, 45(1):104-110.

2. Nguyen, et al: Circulation 2006, 114(11):541.

3. Jain, et al: Circulation 2006, 114(18):II 540b.

4. Noll, et al: MRM 1992, 25(2):319-333.

doi:10.1186/1532-429X-13-S1-P236

Cite this article as: Smith and Nayak: Retrospective slice prescription compensation improves coronary cross-sectional area measurement by MRI. Journal of Cardiovascular Magnetic Resonance 2011 13(Suppl 1):P236.

\section{Submit your next manuscript to BioMed Central} and take full advantage of:

- Convenient online submission

- Thorough peer review

- No space constraints or color figure charges

- Immediate publication on acceptance

- Inclusion in PubMed, CAS, Scopus and Google Scholar

- Research which is freely available for redistribution 